\title{
A percepção de estudantes dos anos iniciais do ensino fundamental sobre a vivência da pesquisa a partir de uma unidade de aprendizagem
}

Lorita Aparecida Veloso Galle loritaveloso@hotmail.com orcid.org/0000-0002-4755-3070 Pontifícia Universidade Católica do Rio Grande do Sul (PUCRS), Porto Alegre, RS, Brasil

Mônica da Silva Gallon monica.gallon@gmail.com $\frac{\text { orcid.org/0000-0003-0793-2372 }}{\text { Pontificia Universidade Cáólica }}$ Grande do Sul (PUCRS), Porto Alegre, RS, Brasil

Alessandra Tatiana Krause Silveira

alekrause@gmail.com

orcid.org/0000-0003-4597-2172

Vinersidade do Vale do Rio do Sinos (UNISINOS), São Leopoldo, RS, Brasil

\section{RESUMO}

\begin{abstract}
O presente artigo tem como objetivo compreender de que modo os estudantes dos anos iniciais do Ensino Fundamental percebem as vivências proporcionadas a partir de uma Unidade de Aprendizagem sobre a origem do planeta Terra e da vida existente nele, na perspectiva da pesquisa em sala de aula. Trata-se de uma pesquisa com abordagem qualitativa, do tipo estudo de caso. Os participantes do estudo foram 23 estudantes do 4은 ano do Ensino Fundamental, de uma escola pública municipal do interior do Rio Grande do Sul. Durante dois meses uma Unidade de Aprendizagem sobre o tema foi desenvolvida, a partir dos interesses expressos em perguntas formuladas pelos próprios estudantes. Após o desenvolvimento da proposta, oito estudantes participaram de uma entrevista semiestruturada, gravada em áudio e, posteriormente transcrita. As respostas foram tratadas via Análise Textual Discursiva. Os resultados fornecem indicativos para assegurar a relevância de propostas metodológicas que valorizem os conhecimentos dos estudantes e seu protagonismo, bem como considerem os seus interesses expressos em perguntas.
\end{abstract} PALAVRAS-CHAVE: Ensino de Ciências. Pesquisa em sala de aula. Unidade de Aprendizagem. 


\section{INTRODUÇÃO}

Considerando as transformações sociais presentes, geradas a partir do progresso impetrado pela tecnologia e pela ciência, parece não ser coerente compreender a educação escolar distanciada da realidade (CARVALHO, 2004). As demandas atuais exigem que os sujeitos sejam capazes de interagir e efetivamente efetuar mudanças alicerçadas no conhecimento. Portanto, é prudente que a educação, em todas as áreas do conhecimento, permita o desenvolvimento de habilidades que levem o estudante a se confrontar com esta sociedade permeada de transformações. Delizoicov, Angotti e Pernambuco (2009, p. 33) compreendem que, diante da diversidade dessas demandas e da facilidade de acesso ao público às informações, as ações desenvolvidas pela escola devem superar as "[...] práticas docentes das décadas anteriores ou da escola de poucos para poucos".

No que diz respeito ao ensino de Ciências, diversos temas têm sido estudados em produções científicas, especialmente quanto à organização curricular, as estratégias e os recursos didáticos. É recorrente nestes estudos que o ensino de Ciências apresente uma abordagem fundada em conceitos, classificações e nomenclaturas, distante das necessidades de uma sociedade em constante transformação (BUENO; FRANZOLIN, 2019). A ruptura desse sistema de orientação curricular nessa área representa um desafio a ser superado e requer esforços de todos os envolvidos. (CACHAPUZ et al., 2011).

Nascimento e Duarte (2014) recomendam que os procedimentos metodológicos adotados no ensino de Ciências nos Anos Iniciais do Ensino Fundamental (EF), apresentem pluralidade no sentido de fomentar o envolvimento dos estudantes. Os autores recomendam que a conduta do professor deve privilegiar o criar, invocar, arriscar e experienciar distintas propostas com vistas a superar a rotina escolar. Para Bueno e Franzolin (2019, p. 390), as condições para que a aprendizagem se efetive com sucesso estão relacionadas diretamente com a diversidade do "[...] meio intelectual, metodológico e didático [...]" no qual os estudantes estão inseridos.

Nesse sentido, ressalta-se a emergência de estratégias diferenciadas a partir de uma prática dialógica que ultrapasse os limites entre componentes curriculares, que seja, "democrática no sentido de oportunizar o protagonismo do estudante, de promover uma educação voltada à reflexão e que incentive a busca de soluções para problemas reais e locais" (LUCA et al., 2018, p. 116).A pesquisa no ambiente escolar emerge como uma possibilidade e pode ser compreendida como um princípio educativo que permite valorizar os conhecimentos constituídos pelos estudantes no decorrer de sua trajetória escolar e, assim, complexificá-los. Tal movimento concede a manifestação do protagonismo desses indivíduos (DEMO, 2015), que passam a atuar não mais como expectadores, mas como agentes de sua própria aprendizagem. Segundo Demo (2012, p. 40) "[...] para o comum dos mortais, pesquisa representa um desafio de reconstrução do conhecimento, partindo do que já se conhece e refazendo o que já está feito".

Uma Unidade de Aprendizagem (UA) pode constituir-se num modo de colocar em prática a pesquisa no âmbito escolar (GALIAZZI; GARCIA; LINDEMANN, 2004). Gonzáles (1999) aponta as UA como uma maneira de superar o planejamento sequencial para o desenvolvimento dos conteúdos, privilegiando a 
ocorrência de trabalhos interdisciplinares. Estudos têm sido desenvolvidos analisando a utilização das UA em diferentes níveis escolares e componentes curriculares (BASSOTO, 2011; CAMARGO, 2013; FARIAS, 2017).

Esta investigação tem como pano de fundo uma UA sobre a origem do planeta Terra e do surgimento dos seres vivos. Após a organização e desenvolvimento desta, que teve como ponto de partida perguntas elaboradas pelos próprios estudantes sobre $\mathrm{o}$ assunto, oito participantes foram entrevistados e após oito meses de realização do projeto, as respostas dos estudantes constituíram o corpus analítico, com o intuito de responder a seguinte pergunta: De que modo os estudantes do EF compreendem as vivências proporcionadas a partir de uma UA sobre a origem do planeta Terra e da vida nele existente, na perspectiva da pesquisa em sala de aula?

O artigo trata inicialmente da pesquisa em sala de aula e apresenta a UA como uma possibilidade de vivenciá-la. Posteriormente é descrito o percurso metodológico do estudo, discutidos os resultados, apresentadas as considerações finais e as referências empregadas.

\section{MARCO TEÓRICO}

Este espaço trata da pesquisa em sala de aula e seus momentos estruturantes: questionamento, construção de argumentos e comunicação. $\mathrm{Na}$ sequência é apresentada a UA como uma possibilidade de realizar pesquisa no âmbito escolar.

\section{A) A pesquisa em sala de aula}

Segundo Demo (2012, p. 43), "[...] o conhecimento não se adquire, repassa, copia, mas se reconstrói, dentro de etapas progressivas e no contato com a realidade e a sociedade". Sendo assim, uma aula convencional, instituída pela mera transmissão de conceitos prontos, pode caracterizar um obstáculo para que os estudantes se apropriem de conhecimentos e possam aplicá-los na resolução de demandas presentes no cotidiano. Compreende-se que este modo de tratamento dos conhecimentos teve alguma valia quando os meios de apropriação eram restritos ao professor como detentor do conhecimento (FREIRE, 2015). Com os avanços tecnológicos e científicos, houve a necessidade de remodelação na forma como o conhecimento se edifica.

Esta reestruturação perpassa o âmbito da sala de aula e as ações educativas presentes neste espaço. Logo, a pesquisa representa uma via de superação de aulas centradas na figura do professor, para a relevância de atividades que valorizem o intercâmbio entre professores e estudantes como parceiros do processo de ensino e aprendizagem (FRISON, 2012).

Pedro Demo (2015, p. 6) apresenta em seu livro Educar pela Pesquisa pressupostos que caracterizam a pesquisa. Destaca a pesquisa como uma conduta inerente à educação escolar, tendo o questionamento reconstrutivo como pilar. $\mathrm{O}$ autor ainda compreende que a pesquisa deve estar inserida na prática habitual de professores e estudantes e, ainda, defende a educação como processo de formação da capacidade humana e histórica. Tais pressupostos 
foram sistematizados de modo prático por Moraes, Galiazzi e Ramos (2012), a partir da pesquisa em sala de aula. Para os autores, há essencialmente três momentos distintos nesta proposta: questionamento, elaboração de argumentos e comunicação.

O questionamento representa o ponto de partida da pesquisa. Freire e Faundez (1985) recomendam que o próprio estudante se envolva neste processo apresentando suas dúvidas e interesses por meio de perguntas. Segundo Ramos (2008), as perguntas formuladas pelos estudantes podem revelar seus interesses, lacunas, fragilidades e, também, conhecimentos já elaborados. Estas informações podem ser consideradas pelo professor no desenvolvimento de seu trabalho. Para Etcheverria (2008), é por meio do questionamento que o estudante desenvolve a crítica e toma consciência de seu entorno, sendo estes fatores relevantes para que o conhecimento evolua.

Porém a pesquisa não se resume apenas ao questionamento, é preciso elaborar argumentos consistentes que possam dar conta de respostas às indagações (MORAES; GALIAZZI; RAMOS, 2012). Conforme Ramos (2012), a argumentação está inserida na necessidade de permanente reconstrução do conhecimento. $\mathrm{O}$ autor avalia que, o desenvolvimento de ações argumentativas demanda a adesão à dúvida. No processo de elaboração de argumentos, é importante recorrer a uma série de estratégias e ferramentas disponibilizadas, admitindo abordagens com perspectivas variadas. A comunicação representa o momento em que os argumentos levantados e sistematizados são divulgados para a apreciação e validação. Outros questionamentos podem emergir neste processo, requerendo a elaboração de novos argumentos que posteriormente são comunicados. Este fato caracteriza a pesquisa como uma espiral inacabada (MORAES; GALIAZZI; RAMOS, 2012).

O produto da pesquisa em sala de aula supera a complexificação de um determinado conhecimento, mas inclui o aprimoramento de capacidades que possibilitam a inserção dos envolvidos nas demandas vigentes com propriedade, considerando os conhecimentos elaborados e validados. É relevante, que diante do modo convencional de abordar os conhecimentos escolares, a instituição da pesquisa represente um desafio tanto aos professores quanto aos estudantes (GALIAZZI, 2014). Nesta perspectiva, a UA pode se constituir em uma possibilidade de efetivar esta proposta (FRESCHI; RAMOS, 2009). A seguir são tratadas algumas compreensões teóricas e práticas deste modo de organização curricular.

\section{B) Superando a aula tradicional: uma UA em ação}

A UA representa uma maneira de orientação dos conteúdos escolares vinculada a pedagogia de projetos de John Dewey, porém sem a consideração excessiva do método científico. Também se insere na proposta construtivista, com a valorização dos participantes de modo a reconstruir seus conhecimentos. A UA leva em conta a superação da disciplinaridade, ao considerar que os conhecimentos de diferentes campos podem dialogar entre si. Além disso, a UA considera os conhecimentos não apenas de técnicos e estudiosos, mas aqueles que foram elaborados ao longo da trajetória de cada um dos envolvidos. (MORAES; GOMES, 2007). 
Ao valorizar a voz dos participantes do processo, a UA permite a superação da aula centrada na figura do professor como o detentor do conhecimento (FREIRE, 2015), admitindo que as ações em sala de aula sejam efetivadas através da colaboração entre professores e estudantes. Assim, uma UA atende as demandas pedagógicas contemporâneas que compreendem a aprendizagem não mais como um processo de transmissão de saberes prontos, mas na reconstrução destes (MORAES, 2010).

Uma UA pode ser organizada a partir de diferentes perspectivas, porém, em linhas gerais, procura partir dos conhecimentos iniciais dos estudantes de maneira a complexificá-los progressivamente. As perguntas elaboradas pelos estudantes propiciam a compreensão dos conhecimentos tácitos de um grupo (MORAES; GOMES, 2007). Portanto, compreende-se que a pesquisa em sala de aula, a partir de suas etapas estruturantes, pode oferecer condições para a reconstrução do conhecimento, sendo a UA uma proposta viável para a sua efetivação (GALIAZZI; GARCIA; LINDEMANN, 2004).

A disposição de uma UA não está fundamentada em uma "receita", pois cada grupo de estudantes pode apresentar demandas e conhecimentos diferenciados. Ainda, deve-se considerar que o ambiente escolar pode oferecer distintos recursos, espaços, materiais e tempos. Destaca-se que a aula, a escola, o professor e os estudantes passam a assumir funções diferentes nesta proposta. A aula deixa de ser o espaço onde o professor determina as ações. A escola passa a desempenhar o papel de preparar os estudantes para atuar na sociedade de modo autônomo, dando conta das demandas com base nos conhecimentos reconstruídos; enquanto o professor ocupa-se do papel de orientar as ações, e os estudantes atuam não mais como ouvintes, mas protagonistas de sua própria aprendizagem (MARTINS, 2001). Cabe destacar que a linguagem é a mediadora deste processo (WERSTCH, 1999).

Sugere-se que as ações educativas desenvolvidas na UA sejam diversificadas e contemplem a participação coletiva com a valorização do contexto em que os estudantes estão inseridos. Destitui-se assim a escola como espaço de reprodução e armazenamento de conhecimentos, promovendo-a para um ambiente em que os estudantes aprendam a exercer esses conhecimentos (DEMO, 2015). A avaliação assume um caráter qualitativo em detrimento ao quantitativo, considerando, entre outros, as produções dos estudantes e a sua participação nas ações discursivas. A prova deve ser encarada apenas como mais um dos instrumentos avaliativos, com o intuito de compreender os avanços e fragilidades do conhecimento dos estudantes e, dessa forma, possibilitar com que o professor dirija as suas ações. É destacável que os próprios estudantes analisem o seu progresso a partir da autoavaliação (MORAES; GOMES, 2007).

\section{PERCURSO METODOLÓGICO}

Este estudo apresenta abordagem qualitativa, o que, segundo Minayo (2012, p.21) focaliza "o universo dos significados" que não são passíveis de quantificação. Optou-se pelo estudo de caso, pois, de acordo com Yin (2015, p. 17), trata-se de uma "investigação empírica que investiga um fenômeno contemporâneo (o 'caso') em profundidade e em seu contexto de mundo real, especialmente quando os limites entre o fenômeno e o contexto puderem não 
ser claramente evidentes". Gil (2002) se refere ao estudo de caso como um estudo que requer profundidade e detalhamento de um ou poucos objetos, permitindo um amplo e aprofundado conhecimento, o que dificilmente pode ser atingido com outros delineamentos, o que justifica, assim esta escolha para a presente pesquisa.

Participaram do estudo 23 estudantes, do 4 o ano do EF de uma escola pública municipal do interior do Rio Grande do Sul, sendo 11 meninos e 12 meninas com idade média de 10 anos. Os participantes da pesquisa estão identificados neste texto pela letra "E" seguida dos números 1 a 8.

Cabe ressaltar que a professora titular da turma, uma das autoras desta pesquisa, atuou também como investigadora da sua própria prática, sendo dessa forma aqui intitulada como professora-pesquisadora. Atitudes que reforçam essa colocação estão na forma como ela conduziu a UA, permitindo que os estudantes manifestassem suas hipóteses e traçando possibilidades para que se consolidasse o processo da aprendizagem. A professora-pesquisadora assume o papel de mediadora na construção do conhecimento junto com os estudantes, tal como requer a pesquisa em sala de aula (MORAES, GALIAZZI; RAMOS, 2012) também precisa ter as suas hipóteses quanto às possíveis aprendizagens e se suas estratégias são assertivas com relação aos objetivos da UA.

A partir de uma conversa informal, sobre o Sistema Solar, a professorapesquisadora solicitou que cada um dos estudantes formulasse, por escrito, pelo menos uma pergunta de seu interesse sobre o tema e apresentasse na aula seguinte. Posteriormente os estudantes socializaram suas perguntas. $O$ conjunto de questionamentos apresentava, em sua maioria, interesses relativos à origem do planeta Terra e o surgimento da vida. Com base nas manifestações expressas nas perguntas, e com a orientação da professora-pesquisadora, os estudantes elegeram a seguinte pergunta que representava, de modo geral, o interesse do grupo: "Como surgiu o planeta Terra e a vida nele?".

$\mathrm{Na}$ sequência, a professora-pesquisadora solicitou aos participantes que propusessem hipóteses às perguntas selecionadas no intuito de orientar a construção de respostas. Após uma discussão conjunta, os estudantes elaboraram as seguintes hipóteses: (a) O planeta surgiu a partir da explosão do Big Bang e a vida nasceu a partir de uma planta que foi gerando outras plantas; (b) O planeta Terra surgiu de uma parte do Sol que foi girando, ao longo dos anos e esfriando; e (c) A vida surgiu a partir das bactérias que se criaram de diversas formas e foram chamadas de seres vivos.

A partir da pergunta elencada e das hipóteses, foi organizada e desenvolvida uma UA. Entre as atividades empregadas, pode-se destacar: consulta em livros e internet, discussão, produção textual, construção de maquetes, apresentação de vídeos e visita guiada ao Museu de História Geológica do Rio Grande do Sul, da Universidade do Rio do Sinos - UNISINOS. As respostas foram implementadas de modo gradativo pela intensa participação dos estudantes em ações distintas orientadas pela professora-pesquisadora. A culminância da pesquisa se deu por meio da comunicação dos resultados, pelos próprios estudantes, em uma Feira de Ciências realizada nas dependências da escola. Este trabalho representa um recorte do estudo efetuado. Posteriormente, transcorrida a UA, oito estudantes foram entrevistados, após seus responsáveis estarem cientes dos objetivos e 
autorizarem por meio do Termo de Consentimento Livre Esclarecido (TCLE) a participação destes.

A construção dos dados se deu por meio de uma entrevista semiestruturada que, segundo Minayo (2012), emprega perguntas abertas e fechadas, autoriza ao entrevistado falar sobre o assunto sem que esteja condicionado somente à pergunta proposta. Após a gravação em áudio das entrevistas, e posterior transcrição, o corpus analítico foi tratado por meio da Análise Textual Discursiva (MORAES; GALIAZZI, 2013). Este método de análise é estruturado a partir de quatro etapas: (a) unitarização: corresponde a desmontagem do corpus em unidades de sentido, com vistas a compreender as ideias proeminentes; (b) categorização: nesta etapa se estabelece as relações entre as unidades de sentido, sendo situadas categorias iniciais, que são então organizadas em categorias mais abrangentes, denominadas categorias intermediárias. Finalmente, estas categorias são organizadas de modo a que se obtenham um número reduzido de categorias finais; (c) construção de metatextos: etapa que se caracteriza pela criteriosa análise das categorias finais visando à elaboração de textos analíticos, que expressem a descrição e interpretação do fenômeno. Estas produções são sucessivamente aprimoradas até que se organize o texto final. (d) comunicação: nesta etapa são divulgados de modo escrito ou oral, os argumentos elaborados no decorrer do processo.

\section{RESULTADOS E DISCUSSÃO}

A partir da análise das entrevistas emergiram duas categorias com vistas a construir resposta ao problema de pesquisa, sendo elas: Percepções dos estudantes à aplicação da UA e Percepções relativas à formulação de perguntas pelos próprios estudantes.

\section{A) Percepções dos estudantes à aplicação da UA}

Nessa categoria foram abarcadas as unidades de sentido cujas manifestações apresentavam as percepções dos estudantes quanto a UA. Evidencia-se nas falas, visões quanto as estratégias empregadas pela professora para operacionalizar a UA e contribuições das UA para a aprendizagem do ponto de vista dos participantes.

Os estudantes demonstraram reconhecer algumas estratégias utilizadas pela professora, como "A profe Ale, ela pediu que a gente trouxesse mais ou menos uma coisa que a gente queria saber mais" (E1) e "[...] a nossa professora pediu pra a gente pensar em alguma coisa em casa que a gente queria saber" (E4). Dessa forma, se torna evidente que o ponto de partida da professora foram os questionamentos que emergiram dos conhecimentos prévios desses estudantes, como dito pelo estudante E2 "Sim, era mais completo [...] a gente tinha que ir buscar coisas e a professora nos ajudava. A gente tinha que dar ideias e nas outras aulas é mais a professora que diz como tem que ser". De acordo com Freschi e Ramos (2009), o professor reúne as atividades que os estudantes conseguem realizar para propor novas estratégias que os estimulem na superação do conhecimento atual. Dessa forma, a professora buscou nas 
perguntas dos estudantes, elementos para a sua própria compreensão do quanto sabiam e como sabiam, para elaborar a aplicação da UA.

A partir desse ponto, percebe-se que os estudantes foram encorajados a buscar respostas às suas perguntas: "A gente teve que buscar muita coisa por nossa conta" (E2). É importante que o estudante se envolva na sua busca pelas respostas aos questionamentos (MORAES; GALIAZZI; RAMOS, 2012), pois, dessa forma, garantem a autonomia para direcionar a pesquisa, de acordo com seu interesse. Esse processo deve acontecer sob a supervisão do professor, que a tudo observa e auxilia: "a professora nos ajudou a fazer isto" (E7); "A professora ia ajudando e nós íamos vencendo" (E5).

Outro destaque diz respeito sobre o fato de os estudantes estarem cientes das etapas as quais a UA está se desenvolvendo. O mapa das atividades que conduzem às aprendizagens pode ser compartilhado com os estudantes, pois assim esses se tornam coparticipes das ações planejadas pelo professor: "O mais importante é que ela explicava sempre como as coisas iam acontecer, que todos tinha que se ajudar" (E7). Essa decisão do professor de envolver o estudante na construção das atividades, de torná-lo ativo não somente na realização, mas conhecedor das etapas pode contribuir na promoção de um espírito de pertencimento e, com isso, uma disposição em colaborar, servindo também de impulso à motivação.

Uma das estratégias adotada pela professora foi a apresentação por meio de uma mostra dos trabalhos das atividades desenvolvidas pelos estudantes ao longo da realização da UA, em uma Feira de Ciências. Constatou-se a consciência dos participantes sobre a etapa de comunicação, exemplificada pela fala do estudante E3: "É porque assim, a gente também gosta de fazer, né, o trabalho. Mas o mais importante acho que é apresentar e mostrar para o público". Outro participante evidencia a comunicação que realizou à família, relatando os achados da turma e tornando-a participante do seu processo de aprendizagem: "[...]nunca imaginava que eu ia aprender tão rápido isso. Porque quando eu cheguei em casa eu falei 'pai, olha o que que eu fiz, pai' e meu pai nem acreditava, nem ele sabia direito. Então, pra mim, eu acho que eu gostei bastante" (E3). Moraes, Galiazzi e Ramos (2012) ressaltam a comunicação dentro do ciclo proposto pela Pesquisa em Sala de Aula como um dos pilares para sua construção.

Sobre as contribuições da UA à aprendizagem, é possível destacar dois pontos relevantes: as percepções sobre o modo de organização da UA em distinção de outras formas de organização das aulas pela docente; e as aprendizagens que os próprios estudantes percebem durante a aplicação da UA.

Os estudantes apontam como diferença a organização das aulas por UA e uma aula tradicional destacando o diálogo, e o reconhecem como uma das estratégias para a construção do conhecimento: "Lendo, conversando. Aprendi também com meus colegas né, porque cada um se ajudava, com a professora" (E3); "Tem bastante diferença, porque daí a gente passa mais tempo conversando e escrevendo o que nós entendemos" (E2). Wertsch (1999) destaca a importância da linguagem, seja ela escrita ou oral para a sistematização e construção de novos conhecimentos.

A interação com os recursos didáticos, incluindo no processo materiais em que os estudantes possam participar, tocar, ou seja, aprender não apenas por 
visualização, mas pelo concreto, também foi apontando como um aspecto que diferencia as UA de outros modos de organização: "[...] foi que a gente podia encostar nos fósseis e que mais importante que a gente aprendeu várias outras coisas" (E3).

A conectividade entre os diferentes conteúdos como forma de responder às suas perguntas emergiu nas falas dos estudantes: "[...] é que, de repente a gente começou aprender sobre uma coisa e já vinha outra coisa junto" (E4), e "Daí tava tudo ligado. Daí a turma toda, tava tudo ligado..." (E1). A interdisciplinaridade é um dos fatores positivos do trabalho desenvolvido por meio da UA (FRESCHI; RAMOS, 2009). Como são privilegiadas as perguntas dos estudantes, não há uma sequência de conteúdos engessados a serem seguidos. As respostas despontam dos questionamentos, trazendo um sentido próprio ao contexto de determinada sala de aula, não sendo passível de serem reproduzidas nos mesmos moldes em outras situações.

Por fim, apontam a participação em grupo, o senso de cooperatividade o ato de aprender a fazer perguntas como os ganhos pessoais da aprendizagem por meio da UA: "[...] eu aprendi a pesquisar, aprendi a fazer perguntas" (E5) e "Eu aprendi que trabalhar em grupo é, como posso dizer, geral mais do que trabalhar solo. Porque o grupo ele pode pensar mais que... tem aquele ditado, duas cabeças é mais esperta que uma" (E1).

A percepção dos estudantes sobre a organização das aulas por meio de uma UA demonstra que estão conscientes que se trata de uma aula diferente dos moldes convencionais, visto que o produto desse processo são estudantes mais participativos, engajados e autônomos para a realização de outras atividades e também para a participação na sociedade.

\section{B) Percepções relativas à formulação de perguntas pelos próprios estudantes}

Nesta categoria foram analisadas as manifestações dos estudantes em relação as perguntas formuladas incialmente por eles, que serviram de base para o desenvolvimento da UA. De modo geral, os estudantes apreciaram a ideia de fazerem perguntas, apresentado como justificativa o fato de ficarem curiosos para aprender e ampliar os seus conhecimentos, como, por exemplo: "Eu me senti curioso, com vontade de aprender mais, porque até certo ponto a gente não sabia quase nada sobre o assunto" (E1) e "Foi legal, por que era a nossa curiosidade e assim a gente ia aprendendo com aquilo" (E5). Segundo Tapia (2005), quando as características de uma determinada atividade instigam a curiosidade, é possível que os envolvidos invistam tempo e atenção, colaborando de modo positivo para que a aprendizagem ocorra.

Os estudantes também destacaram que, ao realizarem as suas próprias perguntas, se sentiram representando os seus próprios interesses, diferente de outras propostas em que as perguntas são geradas a partir de contextos ou formuladas por pessoas externas aos seus processos de aprendizagem. Neste sentido, E3 argumenta sobre a relevância do ato de fazer perguntas: "Porque a professora, no caso nem tinha perguntas assim pra gente fazer. Foi uma iniciativa nossa [...] a gente que teve iniciativa, não foi a professora". Para E1, ao fato de apresentar perguntas também representa um empreendimento pessoal, como justifica em: "Porque a gente podia criar as perguntas [...] não é que nem quando 
a gente é pequeno, e a gente não consegue pensar. A gente criou as perguntas. Ficou um pouco mais legal do que os adultos conseguirem criar as perguntas pra gente". Segundo Freire e Faundez (1985), os questionamentos apresentados pelos estudantes estão ancorados em conhecimentos anteriormente elaborados e, desse modo, apresentam significado para eles.

Sobre a proposição de suas próprias perguntas, os estudantes expressaram não estarem habituados com a sistemática e, por isso, consideraram esta ação um diferencial em relação as demais aulas, a exemplo: "Fazer pergunta foi bem diferente do nosso normal, a gente não tem o costume de fazer uma pergunta [...]" (E7) e, também, "[...] é um ritmo diferente fazer pergunta, a gente responde mais perguntas em aula do que faz" (E2). Esses depoimentos reforçam o fato de as perguntas partirem habitualmente do professor no âmbito da sala de aula, sendo uma das estratégias de ensino mais empregadas (VIEIRA; VIEIRA, 2005). Situação essa que pode levar os estudantes a compreenderem que a sua função é respondê-las e não as formular.

Este fato também pode explicar a dificuldade encontrada pelos estudantes no sentido de organizar as suas ideias para a formulação de perguntas, como, por exemplo: "Foi bem legal [fazer perguntas], mas no início foi complicado para escrever. [...]Tinha um pouco de dificuldade, porque às vezes, tipo tem várias ideias para fazer perguntas e daí não se consegue fazer bem a pergunta" (E7). Os estudantes têm dúvidas, mas como estas quase não são exploradas, é compreensível que tenham dificuldade em organizá-las e traduzi-las em perguntas. Neste sentido Freire e Faundez (1985), compreendem que mais do que ensinar respostas, os professores deveriam ensinar a perguntar, pois é a partir do questionamento que o conhecimento inicia.

O trabalho de busca por respostas para as suas perguntas também foi indicado pelos estudantes como um momento positivo do trabalho, pois possibilitou o exercício do protagonismo destes como agentes de seu próprio aprendizado: "[...] eu me senti, tipo, nossa, eu sou uma cientista, tô procurando a resposta" (E4). E também em: "Eu me senti sabendo um pouco mais. [...] Porque quando eu achei as respostas para essas perguntas eu me senti o cara da sabedoria" (E1). As expressões: "o cara da sabedoria" e "eu sou uma cientista", expressam a realização desses estudantes ao trabalharem buscando respostas para as suas próprias dúvidas. A ampliação da capacidade argumentativa pode conceder o sentimento de empoderamento dos sujeitos, encorajando estes a avançarem de modo autônomo na construção de seu próprio conhecimento (FREIRE; SHOR, 1992).

Os estudantes também reconheceram que $\mathrm{o}$ ato de fazer perguntas se distancia da dinâmica de uma aula tradicional, como manifesta E7 em: "Senti, meio legal assim, meio diferente [...] é diferente tu pesquisar uma coisa nova do teu ritmo de aula". A busca por argumentos às suas próprias perguntas rompe com a aula centrada na figura do professor, que determina as ações no âmbito da sala de aula (FREIRE, 2015). Os estudantes compreendem que o momento de buscar respostas pode admitir que avancem em seu conhecimento, pois outros conhecimentos podem emergir como: "[...]a internet tem várias coisas que a gente pesquisa, daí tem vários sites e essas coisas [...]. E quando a gente se interessa num, daí a gente sabe a resposta para uma pergunta" (E6) e "Eu me senti muito bem, foi bem legal porque a gente descobre coisas novas, é bem 
interessante" (E8). A construção de respostas possibilita que os estudantes ampliem seus conhecimentos à medida que entram em contato com informações derivadas de fontes diversificadas. De acordo com Roden (2010), é importante que os professores, especialmente, dos Anos Iniciais do EF, promovam o contato dos estudantes com recursos diversificados, para que possam construir respostas aos seus questionamentos e, também, ampliá-los.

Com a conclusão dos trabalhos da UA, os estudantes expressaram que de modo geral, sentiram-se mais curiosos e estimulados a fazerem perguntas, justificando, por exemplo, que o contato com diferentes materiais e situações fez com que tivessem novas perguntas, como E1: "[...] porque tu fica pensando... nossa, como eu podia ter perguntado mais um pouco pra saber mais sobre aquela outra coisa"; e E6 expressa em: "Quando a gente começa fazendo uma pergunta [...] começa como uma história, tu começa a fazer uma pergunta e com esta pergunta vai criando várias outras coisas só nessa pergunta". Um ambiente em que o questionamento é fomentado e valorizado, pode se tornar propício à emergência de novas indagações (MENDONÇA; AGUIAR JÚNIOR, 2015).

O exercício de fazer suas próprias perguntas também proporcionou aos estudantes que se sentissem à vontade para realizarem outros questionamentos, rompendo com o constrangimento inicial, como expresso em: "Eu acho que eu fiquei bem mais livre para fazer perguntas, porque eu não gostava muito de fazer perguntas eu era envergonhada [...]. Daí eu acho que fiquei mais curiosa, com vontade de aprender" (E6).

Em outro depoimento também fica evidente a disponibilidade em apresentar mais questionamentos e seguir aprendendo sobre o assunto "[...] eu tinha mais vontade de ir mais além com aquele trabalho de fazer mais perguntas [...] não parar com o assunto" (E2). Neste sentido, é possível compreender que este tipo de trabalho pode fomentar atitudes emancipatórias nos estudantes, permitindo que se sintam "livres" para proporem seus próprios questionamentos, bem como seguir explorando mais sobre o tema (DEMO, 2015).

De modo geral, a proposição de perguntas pelos próprios estudantes na UA foi um exercício positivo, pois claramente fomentou a curiosidade, garantindo aos participantes expressar seus interesses e ampliar seus conhecimentos. Com relação a busca pelas respostas a estas perguntas, os estudantes indicaram que, de fato, sentiram-se protagonistas percebendo em si a aquisição de novos conhecimentos. Também manifestaram que tanto o ato de propor perguntas quanto construir respostas, representou um diferencial em relação às aulas que estão convencionalmente habituados. Com a conclusão dos trabalhos, os estudantes se perceberam mais curiosos e se sentiram instigados a propor novas perguntas.

\section{CONSIDERAÇÕES FINAIS}

Este estudo teve como objetivo responder a seguinte pergunta: De que modo os estudantes do Ensino Fundamental compreendem as vivências proporcionadas a partir de uma Unidade de Aprendizagem sobre a origem do planeta Terra e da vida existente nele, na perspectiva da pesquisa em sala de aula? Os depoimentos trazem indicativos de que os estudantes foram receptivos tanto a proposta da UA, quanto a possibilidade de realizarem perguntas e 
construírem respostas. As falas destacam também que as aulas organizadas deste modo possibilitaram aos estudantes atuarem como protagonistas de sua própria aprendizagem.

O modo de organizar as aulas por meio das UA permite ao docente trazer à luz as curiosidades e os conhecimentos já adquiridos pelos estudantes ao longo da sua escolarização e, também das vivências que os constituem enquanto indivíduos. Ao elaborar perguntas, o estudante demonstra não apenas aquilo que quer saber, mas aquilo que já sabe, fornecendo ao professor subsídios para a construção do planejamento de suas ações com o intuito do ensino e da aprendizagem de um determinado grupo. Por se tratar de uma atividade aplicada a um contexto específico, torna-se difícil a replicação da proposta utilizando os mesmos moldes. O professor necessita adaptar, recriar e trazer novos elementos de acordo com as características de cada grupo sempre que propor alguma atividade semelhante.

A UA promove aprendizagens para além dos conteúdos: uma visão interdisciplinar das situações propostas, o trabalho cooperativo, o diálogo e argumentação entre pares, são exemplos. Proporciona um elo com a família, pois ao contar sobre as atividades desenvolvidas em sala de aula, o estudante pratica suas habilidades de comunicação com um público que mantém laços afetivos e que as críticas podem ser mais bem recebidas. Isso o prepara para, posteriormente, expor a novas audiências, ampliando ainda mais suas habilidades comunicativas e autonomia. O professor também aprende nesse processo: a escutar os estudantes e a partir disso tomar decisões sobre sua prática pedagógica; a circular melhor entre os conteúdos, buscando a interdisciplinaridade necessária às respostas dos estudantes e, perceber que nesse processo seu papel é indispensável no intermédio entre conhecimentos já consolidados e os novos que vão aos poucos sendo elaborados.

Pelas características próprias da UA, pode-se compreender que esta proposta abarca efetivamente aos interesses dos estudantes de modo geral, mas, sobretudo de estudantes dos Anos Iniciais do Ensino Fundamental que, por vezes, trazem inúmeras perguntas para a sala de aula. A singularidade desta proposta permite o envolvimento dos estudantes e também pode superar a rotina escolar, fatores que colaboram para o ensino e aprendizagem de Ciências neste nível escolar. Trata-se de um desafio para o professor que terá que rever a sua prática no sentido de orientar os estudantes na busca pelas respostas.

Como modo de avançar o estudo, cabe destacar a relevância da apropriação de professores em formação de pressupostos da pesquisa em sala de aula, bem como estratégias que viabilizam a sua aplicação em diferentes contextos. 


\title{
The perception of elementary school students about the experience of research from a learning unit
}

\begin{abstract}
The aim of this article is to understand how the elementary school students perceive the experiences provided by a Learning Unit about the origin of the planet Earth and the life that exists in it, from the perspective of classroom research. It is a research with qualitative approach of the case study type. The study participants were 23 students from the 4th year of Elementary School, primary years, from a municipal public school in the countryside of Rio Grande do Sul. During two months a Learning Unit on the theme was developed, based on the interests expressed in questions formulated by the students themselves. After the proposal was developed, eight students participated in a semistructured interview, recorded in audio and later transcribed. The answers were treated via Discursive Textual Analysis. The results provide indications to ensure the relevance of methodological proposals that value the students' knowledge and their protagonist, as well as consider their interests expressed in questions.
\end{abstract}

KEYWORDS: Science Teaching. Classroom Research. Learning Unit. 


\section{REFERÊNCIAS}

BASSOTTO, G. V. Nanotecnologia: uma investigação fundamentada na educação pela pesquisa se refletindo na formação de professores e no ensino de química. 2011. 130 f. Dissertação (Mestrado em Educação em Ciências e Matemática) Faculdade de Física, Pontifícia Universidade Católica do Rio Grande do Sul, Porto Alegre, 2011.

BUENO, K. C.; FRANZOLIN, F. A utilização de procedimentos didáticos nas aulas de Ciências Naturais dos anos iniciais do ensino fundamental. Revista Electrónica de Enseñanza de las Ciencias, v. 18, n. 2, p. 387-412, 2019.

CACHAPUZ, A.; GIL-PÉREZ, D.; CARVALHO, A. M. P.; PRAIA, J.; VILCHES, A. (Orgs.). Necessária renovação do ensino de ciências. 3. ed. São Paulo: Cortez, 2011.

CAMARGO, A. N. B. A influência da pergunta do aluno na aprendizagem: o questionamento na sala de aula de química e o educar pela pesquisa. 2013. $110 \mathrm{f}$. Dissertação (Mestrado Educação em Ciências e Matemática) - Pontifícia Universidade Católica do Rio Grande do Sul, Porto Alegre, 2013.

CARVALHO, A. M. P. (Org.). Ensino de Ciências: unindo a pesquisa e a prática. São Paulo: Pioneira Thomson Learning, 2004.

DELIZOICOV, D; ANGOTTI, J. A.; PERNAMBUCO, M. M. Ensino de Ciências: fundamentos e métodos. 3. ed. São Paulo: Cortez, 2009.

DEMO, P. Desafios modernos da educação. 18. ed. Petrópolis: Vozes, 2012.

DEMO, P. Educar pela pesquisa. 10. ed. Campinas: Autores Associados, 2015.

ETCHEVERRIA. T. C. A problematização no processo de construção do conhecimento. In: GALIAZZI, M. C.; AUTH, M.; MORAES, R.; MANCUSO, R. Aprender em rede na Educação em Ciências, Ijuí: Unijuí, 2008, p. 77-89.

FARIAS, B. M. P. Água como temática no Ensino de Química na Educação de Jovens e Adultos. 2017. 90f. Dissertação (Mestrado em Ensino de Ciências e Matemática) - Faculdade de Educação, Universidade Federal de Pelotas, 2017.

FREIRE, P. Pedagogia do oprimido. 59. ed. Rio de Janeiro: Paz e Terra, 2015.

FREIRE, P.; FAUnDEZ, A. Por uma Pedagogia da Pergunta. 2 ed. Rio de Janeiro: Paz e Terra, 1985.

FREIRE, P.; SHOR, I. Medo e ousadia: O cotidiano do professor. 4. ed. Rio de Janeiro: Paz e Terra, 1992.

FRESCHI. M; RAMOS, M. G. Unidade de Aprendizagem: um processo em construção que possibilita o trânsito entre senso comum e conhecimento científico. Revista Electrónica de Enseñanza de las Ciencias, v. 8, n. 1, p. 156-170, 2009. 
FRISON, L. M. B. Pesquisa como superação da aula copiada. In: MORAES, R.; LIMA, V. M. R. (Orgs.) Pesquisa em sala de aula: tendência para a educação em novos tempos. Porto Alegre: EDIPUCRS, 2012, p. 105-115.

GALIAZZI, M. C. Educar pela pesquisa: ambiente de formação de professores de Ciências. Ijuí: Unijuí, 2014.

GALIAZZI, M. C.; GARCIA, F. A.; LINDEMANN, R. H. Construindo caleidoscópios: organizando unidades de aprendizagem. In: MORAES, R.; MANCUSO, R. (Orgs.). Educação em Ciências: produção de currículos e formação de professores. Ijuí: Unijuí, 2004.

GIL, A. C. Como elaborar projetos de pesquisa. 4 ed. São Paulo: Atlas, 2002.

GONZÁLES, J. F. et al. ¿Como hacer Unidades didácticas innovadoras? Sevilla: Diada, 1999.

LUCA, A. G.; SANTOS, S. A.; DEL PINO, J. C.; PIZZATO, M. C. As marcas de aprendizagem por meio da pesquisa, da escrita e da leitura de livros de divulgação científica: uma possibilidade para a sala de aula. ACTIO, Curitiba, v. 3, n. 2, p. 116-132, 2018.

MARTINS, J. S. O trabalho com projetos de pesquisa: do Ensino Fundamental ao Ensino Médio. Campinas, Papirus, 2001.

MENDONÇA, D. H.; AGUIAR JÚNIOR, O. G. Análise das interações discursivas em uma sala de aula de ciências: estratégias do professor frente às perguntas dos estudantes. Anais do X Encontro Nacional de Pesquisa em Educação em Ciências-ENPEC, 2015.

MINAYO, M. C. S.; O desafio da pesquisa social. In: MINAYO, M. C. S.; DESLANDES, S. F.; GOMES, R. Pesquisa social: teoria, método e criatividade. 32. ed. Rio de Janeiro: Vozes, 2012. p. 9-29.

MORAES, R. O significado do aprender: linguagem e pesquisa na reconstrução de conhecimentos. CONJECTURA: filosofia e educação, v. 15, n. 1, p. 135-150, 2010.

MORAES, R.; GALIAZZI, M. do C. Análise Textual Discursiva. 2. ed. Ijuí: Unijuí, 2013.

MORAES, R.; GALIAZZI, M.C.; RAMOS, M. G. A pesquisa em sala de aula: fundamentos e pressupostos. In: MORAES, R.; LIMA, V. M. R. (Orgs.) Pesquisa em sala de aula: tendência para a educação em novos tempos. Porto Alegre: EDIPUCRS, 2012, p. 11-20.

MORAES, R.; GOMES, V. Uma unidade de aprendizagem sobre unidades de aprendizagem. In: GALIAZZI, M. C.et al. (Org.). Construção curricular em rede na educação em ciências: uma aposta de pesquisa na sala de aula. ljuí: Unijuí, p. 243-280, 2007. 
NASCIMENTO, T. A.; DUARTE, A. C. S. Estratégias pedagógicas do ensino de ciências no Fundamental I: Uma análise a partir de dissertações. Revista SBEnBio, v. 7, p. 7077-7084, 2014.

RAMOS, M. G. A importância da problematização no conhecer e no saber em Ciências. In: GALIAZZI, M. C.; AUTH, M.; MORAES, R.; MANCUSO, R. Aprender em rede na Educação em Ciências, ljuí: Unijuí, 2008, p. 57-76.

RAMOS, M. G. Educar pela pesquisa é educar para a argumentação. In: MORAES, R.; LIMA, V. M. R. (Orgs.) Pesquisa em sala de aula: tendência para a educação em novos tempos. Porto Alegre: EDIPUCRS, 2012, p. 21-38.

RODEN, J. Levantamento e análise de questões e o uso de fontes secundárias. In: WARD, H.; RODEN, J.; HEWLETT, C. FOREMAN, J. Ensino de Ciências. Tradução de Ronaldo Cataldo Costa. 2. ed. Artmed Editora, 2010.p. 64-82.

TAPIA, J. A. Motivar em la escuela, motivar em la familia. Madri: Morata, 2005.

VIEIRA, R. M.; VIEIRA, C. Estratégias de ensino/aprendizagem: questionamento promotor do pensamento crítico. Instituto Piaget: Lisboa, 2005.

WERTSCH, J. V. La mente em acción. Buenos Aires: Aiqué, 1999.

YIN, R. K. Estudo de caso: planejamento e métodos. 5 ed. Porto Alegre: Bookman, 2015.

Recebido: 19 ago. 2019.

Aprovado: 21 out. 2019

DOI: 10.3895 /actio.v4n3.10559

Como citar:

GALLE, L. Ap. V.; GALLON, M. da S.; SILVEIRA, A. T. K. A percepção de estudantes dos anos iniciais do

Ensino Fundamental sobre a vivência da pesquisa a partir de uma unidade de aprendizagem. ACTIO,

Curitiba, v. 4, n. 3, p. 449-464, set./dez. 2019. Disponível em: https://periodicos.utfpr.edu.br/actio. Acesso em:

$\mathrm{XXX}$

Correspondência:

Lorita Aparecida Veloso Galle

Rua Gomes Jardim, 58. Bairro:Vila Schell. Três Coroas, RS.

Direito autoral: Este artigo está licenciado sob os termos da Licença Creative Commons-Atribuição 4.0

Internacional.

(c) (1) 